\title{
A collaborative research project on evidence-based and eco-effective design
}

\author{
Mardelle M. Shepley ${ }^{1}$, Mara Baum ${ }^{2}$, and Bill Rostenberg ${ }^{2}$ \\ ${ }^{1}$ Texas A\&M University, College Station, Texas \\ ${ }^{2}$ Anshen+Allen, San Francisco, California
}

\begin{abstract}
The primary purpose of this study was to provide information regarding the design of healthcare facilities in the context of two important considerations, evidence-based design (EBD) and eco-effective design (EED). The secondary purpose was to test the effectiveness of research involving collaboration between practitioners and academic researchers, and the collaboration between EBD and EED professionals. The research team included designers and staff from a firm specializing in EBD and EED and a university researcher. Methods employed included focus groups, snowball surveys, and questionnaires. Practitioner focus groups specializing in EBD and EED identified critical questions that were translated into a 22-question, Likert and narrative-response survey. EBD and EED experts, via a snowball survey, selected the best practice institutions that would be the most appropriate recipients of a questionnaire that would address the role of EBD and EED. Administrators, representing these institutions, participated in the survey. This study is significant in that it demonstrates that in spite of prior perceptions that EBD and EED are in conflict with one another, administrators perceived the two as being fundamentally compatible. This conclusion is useful to designers and facility administrators by freeing them to incorporate both of these critical approaches in the design of new facilities. Observations are made regarding the collaborative process between practitioners and researchers.
\end{abstract}

Conference theme: Collaborative and interdisciplinary research, education, and design

Keywords: evidence-based design, sustainable design, eco-effective design, healthcare, interdisciplinary research

\section{INTRODUCTION}

The official birth of design research can be traced to the publication of work by individuals such as E.T. Hall in the 1950s, and the founding of the Environmental Design Research Association in 1968. Since then, topics for architectural research have typically been generated from within academe. More recently, however, healthcare designers, who are now aware of the meaning and implications of incorporating the results of studies in design, are sharing their informational needs with researchers and engaging in cooperative investigatory efforts. The potential impact and effectiveness of this interaction is one of the "lessons learned" from this study.

In keeping with this collaborative approach, the authors of this paper represent an alliance between a large design firm and a university researcher. While 10 years ago, few firms participated in research, the integration of research and practice is becoming more common. Several firms have hired research directors and staff, and a group has been established (Researchers in Professional Practice (RIPP)) to share the experiences of firm-based researchers and discuss the nature of research projects that are being conducted in design offices.

The topic of the research project described here stemmed from an issue that confronted the practitioners that initiated this study in their healthcare design practice - the perceived conflict between two important considerations, evidence-based design and eco-effective design. While evidence-based design has been a key factor in the design of healthcare facilities for the last 20 years, eco-effective design and related sustainability issues have only recently become a driving force in healthcare design.

For many years, it was believed that the constraints of hospital design would prohibit eco-effective and sustainable design. This has now been clearly disproven; two recent healthcare facilities have been accorded LEED Platinum status (Dell Children's Medical Center in Austin, Texas and the Center for Health and Healing at Oregon Health and Science University in Portland, Oregon), and many facility owners are committed to sustainable facility design and operation. Additionally, LEED for Healthcare credits will be incorporated into the upcoming release of LEED in 2009.

Designers and facility administrators and managers have disparate opinions regarding the relationship of 
these two approaches. Some argue that the two are mutually supportive or closely aligned, while others suggest that they are incompatible or unrelated. The primary purpose of this study was to provide data that would help clarify the relationship between these two approaches as perceived by healthcare facility administrators.

\section{LITERATURE REVIEW}

\subsection{Definitions}

Evidence-based design. Although the term was not in common use until the late 1990s, the first conference that raised the issue of the importance of design research in healthcare was held in 1988 (National Symposium on Healthcare Interior Design). Evidencebased design encompasses the design and operation of buildings to support positive health outcomes in the built environment through an expanding collection of solutions informed by research and practical knowledge (Hamilton 2003). The range of topics associated with evidence-based design is vast and thought by some to include research associated with sustainability and health. More mainstream topics include research associated with increased patient and staff safety, family satisfaction, staff efficiency, and access to positive distraction.

Eco-effective design. William McDonough and Michael Braungart (2002) describe eco-effective design as a design approach that strives to create ecological, social and economic value instead of generating waste or other negative by-products. Eco-effective design is a form of sustainable design in which the emphasis is on creating environments that accomplish more than ecological efficiency; proponents of EED focus on building projects, which have a positive impact on the natural environment.

Of the two approaches, EBD has a longer history as an approach to healthcare design and has been the primary innovative force in this specialization since the 1980s. However, both approaches continue to evolve; hence, their definitions are shifting, and potentially melding, over time.

\subsection{Relationship between EED and EBD}

Overall, authors who publish on the relationship between EED and EBD are divided in their perspectives; many claim that the two are connected and support one another (e.g., Guenther, et al. 2006); while others suggest that they are in conflict (e.g. Harvie 2006). While a number of studies have been recently completed or are currently underway that assess either sustainability in the built environment or investigate the relationship between building design and health outcomes, the relationship between the two approaches is rarely (if ever) incorporated (Shepley, Baum, Ginsberg \& Rostenberg, in press). Often journals will pair articles on these topics in the same issue (e,g, Eagle 2005; Zimmerman 2008). This approach indicates that the editors realize that both subjects are important to healthcare design, however, the direct and indirect relationships between the two are not explored. Few studies have addressed both evidence-based design and eco-effective design in relation to each other.

\section{METHODOLOGY}

\subsection{Collaboration between designers \& researchers} The principal investigators in this study came from practice and academe, although all participants currently have or previously have had extensive experience in the others domain. As such, the researchers perceived their perspectives as completely compatible and took advantage of one another's strengths by building on their combined skill sets.

The research team members concur with Radu, in that there is "no axiological difference between architectural design and scientific research" (Radu 2006:350). Radu notes that the processes are similar, both relying on the incorporation of knowledge, heuristic process, and consensus. In both cases, outcomes cannot be guaranteed,

\begin{abstract}
Scientific research and architectural design are activities possessing their own risks. They create results covering an entire range from bad to outstanding. They have similar limits relating to their communication and the vulgarization of their generative process. The discipline of architecture reveals 'a human capacity (architectural design) performing at its most routine and as well as at its highest level of complexity. It is closer to human sciences than to natural sciences (Radu 2006:348).
\end{abstract}

The practitioners and researcher interacted both in tandem and sequentially. The activities described in Fig. 1 demonstrate the frequent "handing off of the baton" during the research sequence of idea generation, data collection/analysis, and dissemination. Occasionally, simultaneous collaboration was essential when skill sets overlapped (e.g. generating a list of subject sites, developing the survey, and disseminating the results). Firm representatives and the researcher collaborated in the idea generation phase, while data collection and analysis was conducted by the academic researcher as part of an effort to provide consistency in data retrieval protocols and to maintain objectivity in reviewing the data. The practitioners provided oversight and the benefit of their experience to the development of the research project. Likewise, the university researcher provided input on the contributions of the practitioners. The investigators shared in process of disseminating the results, with the objective of reaching as broad an audience as possible.

\subsection{Collaboration between EED and EBD practitioners and researchers}

The principal investigators also represented different specializations - eco-effective design and evidencebased design. The opportunity for interaction between these members of the research team was felt to be one of the more important outcomes of the study. While working together to identify the project objectives they became more aware of ways in which they could 
support one another's design intentions. One investigator, who specialized in EBD, was motivated to pursue the LEED certification process during the course of the study.

Table 1: Collaborator Roles.

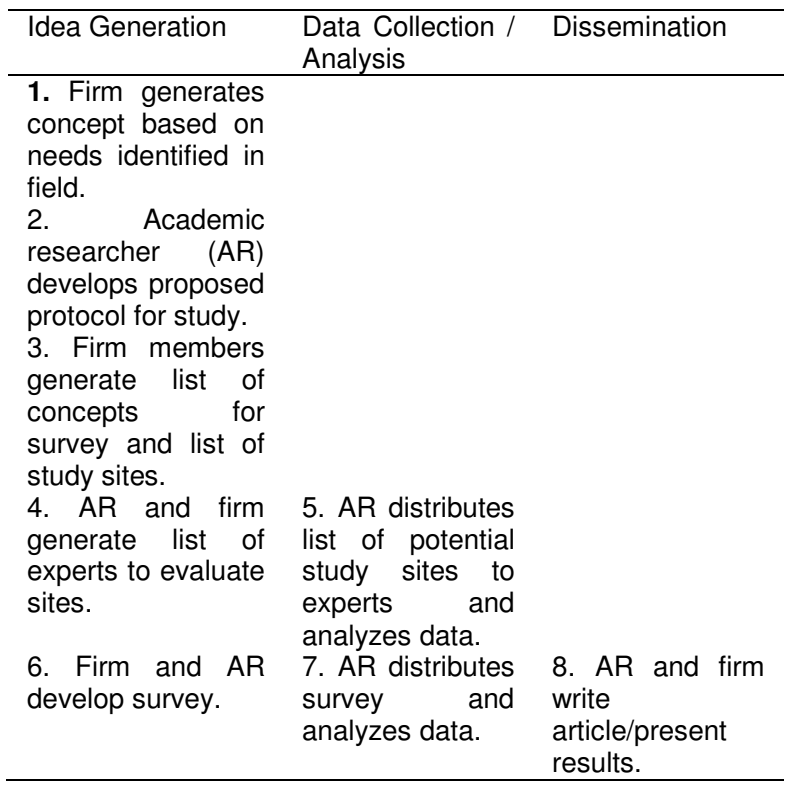

\subsection{Hypotheses}

The primary hypothesis of this study was that evidencebased design and eco-effective design are compatible approaches when designing healthcare facilities. At the same time, the researchers conceded that there were some minor conflicts (e.g., infection resistant materials, which support the infection control objectives of EBD, are not easily recyclable and therefore are in conflict with the tenets of EED), and a few objectives that were neither synergistic nor contradictory. For example, storm water management would probably not have any direct effect on the health and behavioural outcomes of inpatients.

\subsection{Instruments}

The research for this project involved four tools each of which was meant to inform the subsequent research phase. These tools included: 1) practitioner focus groups, 2) snowball sampling for the identification of experts, 3) a best practice facility survey, and 4) the EBD/EED questionnaire. The final phase of the study was dissemination, a priority to meet the applied research objectives of the investigators. These steps, along with information regarding the participation of the practitioners and the academic in each phase, are described in Fig. 2.

The process for each of the four research steps, leading to dissemination (Section 2.9), is summarized in Sections 2.5, 2.6, 2.7 and 2.8. While it might have been possible to generate the healthcare facility administrators' questionnaire without the input of focus and expert groups, the insertion of these steps increased the clarity and objectivity of the survey tool.
The details regarding this methodology are provided in Shepley, Baum, Ginsberg \& Rostenberg (in press).

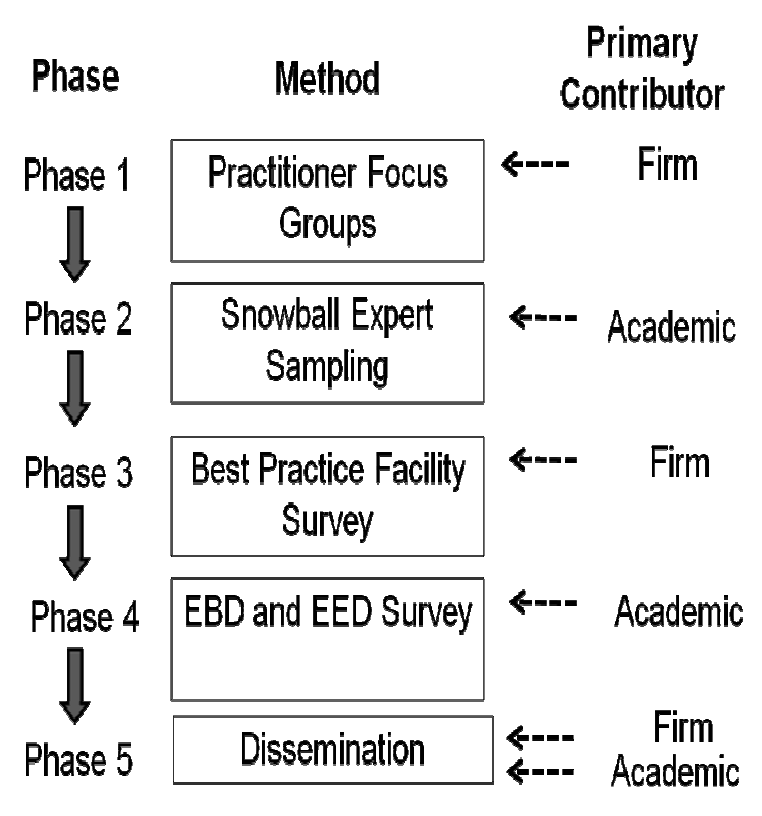

Figure 2: Phases.

\subsection{Practitioner focus groups}

Phase 1, practitioner focus groups, involved meetings with experts in the design firm. These participants helped to frame the concept behind the study (e.g. perceived synergy and conflict between evidencebased design and eco-effective design) and generated questions that to be included in the Phase 4, administrator survey. Some of the contributors specialized in EBD and others specialized in EED. Although several focus group members were familiar with and supportive of both approaches, none were expert in both. Once the questions were developed, the next challenge was to identify the healthcare facilities that would serve as the sites from which respondents would be solicited. The practitioner focus group and practitioner researchers generated a list of potential best practice EBD and EED healthcare facilities that would be presented to EBD and EED experts for ranking in the best practice facility survey.

\subsection{Snowball expert sampling}

To determine which facilities on the preliminary list were the most exceptional, the research team needed input from experts in EBD and EED. In Phase 2, therefore, the research team members collaborated to generate a group of experts who would ultimately review the nominees for best practice. Using a "snowball" method, recommendations for members of the panel of experts were gathered, first from the research team and then from the experts themselves. Once the recommendations for experts began to be repeated and new names we no longer provided, it was evident that the majority of expert candidates had been identified. 


\subsection{Best practice facility survey}

The lists of best practice facilities were distributed by email to the experts identified in Phase 3, based on their specializations. A follow up by phone was necessary in a few cases, when no response was received, and in two cases the experts were approached in person. Each expert was asked to identify the top 10 facilities from the list that was provided, which best exemplified either EBD or EED principles, depending on the individual's specialization. They were also invited to add building projects to the list, if they felt an appropriate candidate for best practice was not included.

Twenty-six leading researchers and practitioners in each field were contacted to identify the healthcare facilities that most successfully embodied evidencebased or eco-effective design best practice principles.

\subsection{EBD and EED survey}

Phase 4, the EBD and EED survey, combined the information gathered in phases 1 (focus groups), 2 (snowball expert survey) and 3 (best practice survey). In Phase 1, practitioner focus groups specializing in each of these fields within the design firm identified critical questions that were translated into a 22question, Likert and narrative-response survey. Phase 2 allowed the researchers to identify the experts who could identify the subject sites. Phase 3 finalized the sites from which administrator/respondents were selected.

In Phase 4, an administrator (typically a CEO or director of facilities) involved in the design of each the 18 best practice institutions (9 EED and 9 EBD) was asked to respond to the survey. The following were among the 22 questions:

1. To what extent did EBD/EED play a role in the design process?

2. To what extent is EBD/EED considered when making decisions regarding facilities, and clinical or administrative issues?

3. Are you collecting or have you collected data related to $\mathrm{EBD} / \mathrm{EED}$ ?

4. If you incorporated EBD/EED practices in your facility, are you collecting or have you collected...data related to EED/EBD?

5. Were there EBD/EED strategies that you considered but did not include in the project as a result of conflicts with the goals of EED/EBD best practices?

6. If you were to rebuild your facility, what changes might you make with regard to evidence-based goals?

\subsection{Dissemination.}

Dissemination was considered to be a critical phase of the research. Additionally, it was important to the research team that the study be useful to both academics and practitioners. As such it was decided that the findings should be published and presented in multiple forums, and communicated in formats that were compatible with each group.

\section{RESULTS}

\subsection{Introduction}

The data gathered at each phase of the project were used to inform the subsequent phase. The details of the results of this portion of this study are provided in Shepley, Baum, Ginsberg, and Rostenberg (in press).

\subsection{Practitioner focus groups}

Participants in the focus groups identified 10 primary issues for the survey ranging from the degree to which EBD or EED was incorporated in the completed facilities to perceived conflicts between the two approaches. Thirty-one EBD and fifty-two EED projects were selected for the pool of potential best practice facilities.

\subsection{Snowball expert sampling}

Fifty-two experts were contacted to select best practice projects. Twenty-six were EBD experts and 26 specialized in EED. The experts were from universities, professional practice, and organizations whose missions focused on evidence-based design or sustainability.

\subsection{Best practice facility surveys}

Of the 26 EBD and 26 EED experts who were approached, 16 EBD experts and 16 EED experts responded, representing $62 \%$ of the total subject population. Those projects that had a sufficient number of recommendations to be among the top-third were included in the study. As a result, 9 EBD and 9 EED projects were selected to participate in the survey process. With respect to EBD facilities, there was significant agreement regarding which facilities were most exemplary, and all those in the top-third had 6 or more votes. However, in the case of EED, some of the top-third projects only had 3 votes. Only one additional project was suggested as a result of allowing respondents to add to the pool, and the majority of experts selected fewer than 10 of the potential best practice facilities.

\subsection{EBD and EED survey}

The primary issues addressed by the survey fell into the categories of supportiveness and conflicts, frequency of data collection, decision-making and design process, and impacts of EBD and EED on the facilities.

Supportiveness and conflicts. Approximately 50\% of the respondents saw the two approaches as supportive, while about $15 \%$ felt there was no relationship at all. Only $10 \%$ perceived the incorporation of both approaches as generating conflicts. (The remainder perceived the relationship to be not applicable to their facility.)

In general, EBD was perceived to have a positive relationship to sustainability, particularly with regard to access to nature, provision of positive distractions such 
as art, entertainment and music, choice, infection control, and proper acoustics and lighting. Interestingly, acoustics and lighting were also one of only two EBD factors that were considered to be problematic for EED. Staff support was the second EBD factor considered by some to conflict with EED.

However, Fig. 3 demonstrates that at an average of $50 \%$ of the respondents saw EBD strategies as having a positive impact on sustainability, regardless of the EBD characteristic. Beyond this, approximately $45 \%$ saw it as having no impact at all.

Consensus was not as strong regarding the impact of EED issues on health in EED facilities. Four items, sustainable landscape, water efficiency, reuse of rain water and mechanical systems developed to improve air quality were perceived to be potentially problematic regarding their impact on EBD by a small percentage of the respondents. These same items also received a high number of votes suggesting that EED had no impact on EEB health goals. On the other hand, nature and daylight received unanimous support in terms of their positive impact on health.

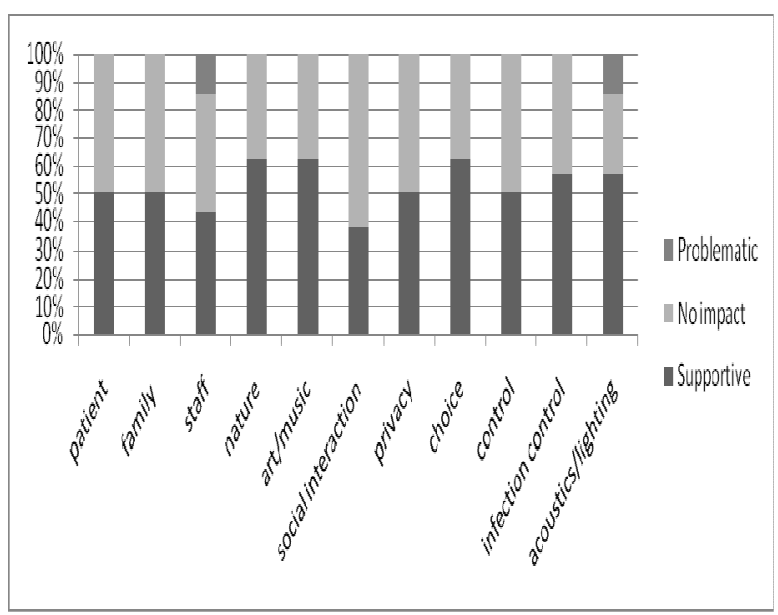

Figure 3: Impact of EBD Issues on EED in EBD Facilities. (Shepley, Baum, Ginsberg \& Rostenberg, in press)

Frequency of data collection. Regarding frequency of data collection on evidence-based design and ecoeffective design, the researchers found that more than $85 \%$ of EBD facilities were gathering data on EBD, although only about $12 \%$ were collecting data on EED. Data collection in the EED facilities on EED characteristics was less common. Slightly fewer than $50 \%$ of EED facilities were gathering data on EED. Surprisingly, the EED facilities were more interested in outcomes on EBD amenities, hence, more than $60 \%$ were gathering data on EBD.

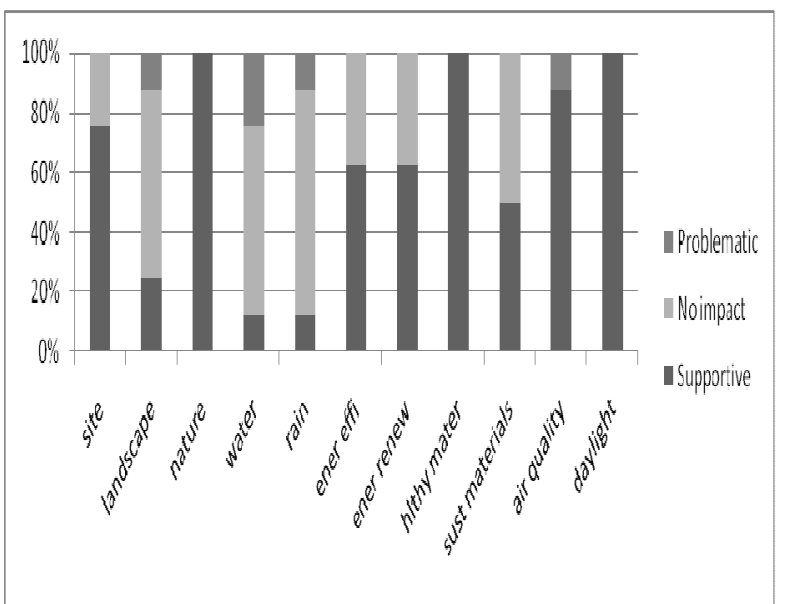

Figure 4: Impact of EED Issues on Health in EED Facilities. (Shepley, Baum, Ginsberg \& Rostenberg, in press)

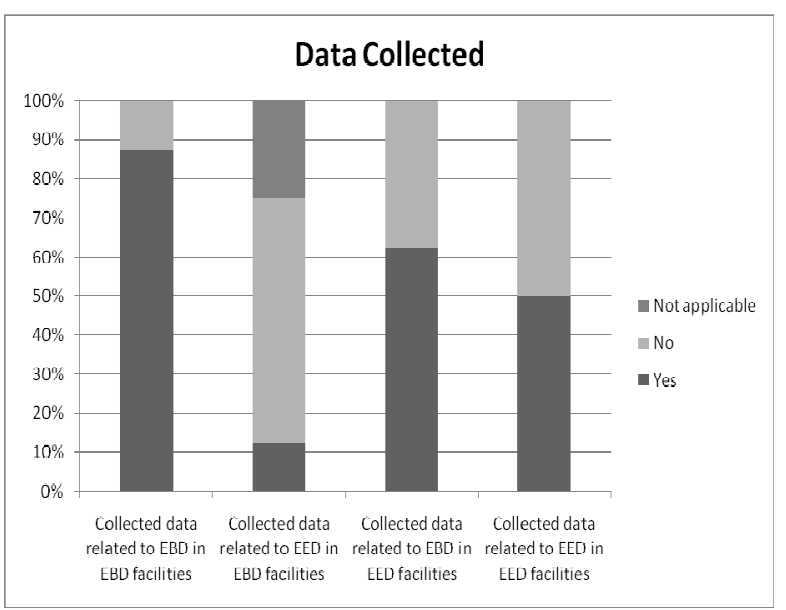

Figure 5: EED/EEB Frequency of Data Collection.

Decision making and design. The impact of these two approaches on decision-making and design was a focus of this research project. In EBD almost $80 \%$ of the facilities took EBD into consideration at a moderate or significant level, and a substantial number (approximately 65\%) considered sustainability. In EED facilities, EBD is considered to play a moderate to significant role in decision-making $100 \%$ of the time, while EED plays a moderate to significant role in decision-making about $90 \%$ of the time.

\subsection{Dissemination.}

The investigators alternated the writing lead and first authorship on the development of two articles, one appearing in a peer-reviewed journal (Shepley, Baum, Ginsberg \& Rostenberg, in press) and others appearing as publications through the two grant-awarding agencies, the Boston Society of Architects (Baum, Shepley, \& Rostenberg, in review a) and the American Institute of Architects Upjohn Initiative. The work was submitted to three conferences one focused on 
academic research, one focused on health facility design, and the other focused on sustainable design.

\section{DISCUSSION AND CONCLUSION}

\subsection{Relationship of EBD and EED}

This study is significant in that it demonstrates that in spite of prior perceptions that EBD and EED are in conflict with one another, administrators perceived the two as being fundamentally compatible. This conclusion is useful to designers and facility administrators by freeing them to incorporate both of these critical approaches in the design of new facilities. Supportiveness and conflicts. Overall, administrators suggested that while there are some conflicts between the two approaches, evidence-based design and ecoeffective design are fundamentally compatible. This is not surprising in light of the fact that both these approaches address the health of people as impacted by the physical environment. The outcome of this study is reinforced by subsequent discussions with EED experts, who suggested that evidence-based design is a subset of sustainable design, and EBD experts, who describe sustainable design as a subset of evidence-based design. A more likely position is that their objectives are inextricably linked in a parallel effort to create socially responsible architecture.

Frequency of data collection. The study indicated that follow up research on EBD is being conducted at most best practice institutions. An interesting finding, however, was the lack of follow-up research being done on EED in EED healthcare environments. The authors of this article strongly recommend that building evaluations be conducted on all projects that have incorporated eco-effective design principles. With regard to the relationship between EED and EBD, research focusing on their impact on one another would help to clarify a collaborative agenda.

Decision-making and design. Surprisingly, evidencebased design played a bigger role in ongoing decisionmaking than eco-effective design in both types of best practice facilities. An increase in the impact of sustainable design will likely result from the institution of the new LEED guidelines for healthcare facilities.

\subsection{Firm and researcher collaboration}

The research collaboration represented by this project strived to overcome the multiple factors that have historically inhibited the integration of research into the practice of architecture, including: 1) difficulties in communication between academics and practitioners (few journals or conferences shared by both groups, lack of clarity about application of research results, etc.), 2) the time required to gather research relative to the immediate needs of a project in progress, 3) a lack of understanding of the nature of research and its potential contribution to building design, and 4) a lack of individuals who are trained both as researchers and designers to serve as translators. Partnership between researchers with design backgrounds and designers with research backgrounds gives this type of investigation roots in both realms. It also represents a rare partnership between individuals focused on evidence-based design to join those engaged in ecoeffective design.

The collaborative process merged strengths of academia and professional practice. The impartiality and rigorous methodology of science wedded to the "in the trenches" knowledge of issues that drive built projects provided the ideal blending required for good healthcare design.

\section{ACKNOWLEDGMENTS}

Funds for this project were provided by AIA Upjohn Initiative and the Boston Society of Architects Research Grants in Architecture program. The authors would like to acknowledge the contributions of Rachel Ginsberg of Anshen+Allen and Samira Pasha of Texas A\&M University.

\section{REFERENCES}

Baum, M., Shepley, M., \& Rostenberg, B. (In review a). Evidence-based design and eco-effective design: Removing the barriers to integration. Boston, MA: Boston Society of Architects.

Eagle, A. 2005. Taking the LEED: Environmentally Friendly Design and Construction Earns Distinction. Health Facilities Management, 18 (6) 10-19.

Guenther, R. Vittori, G. \& Atwood, C. 2006. Valuesdriven design and construction: Enriching community benefits through green hospitals. In Designing for the $21^{\text {st }}$ century hospital. Papers presented by the Center for Health Design and Health Care without Harm at a conference sponsored by the Robert Wood Johnson Foundation, September 2006. Hackensack, NJ.

Hamilton, D. 2003. The four levels of evidence-based design practice. Healthcare Design, 3, 18-26.

Harvie, J. 2006. Redefining healthy food: An ecological health approach to food production, distribution, and procurement. In Designing for the $21^{\text {st }}$ century hospital. Papers presented by the Center for Health Design and Health Care Without Harm at a conference sponsored by the Robert Wood Johnson Foundation. September 2006, Hackensack, NJ.

McDonough, W. \& Braungart, M. 2002. Cradle to cradle: Remaking the way we make things. NY, NY: North Point Press.

Radu, F. 2006. Inside looking out: a framework for discussing the question of architectural design doctorates. The Journal of Architecture, 11 (3), 345351.

Shepley, M. Baum, M., Ginsberg, R. \& Rostenberg, B. (in press ). Eco-effective design and evidence-based design: Healthcare Facility Administrators' Perceptions 
of Synergy and Conflict between Two Approaches. Health Environments Research and Design, 3 (2).

\section{BIBLIOGRAPHY}

Carpenter, D. 2008. Greening up: Hospitals getting savvier on sustainability. Health Facilities Management, $21(7), 15-21$.

Clitheroe, H. 2000. Mapping the Creative Context of Architects. Doctoral dissertation, University of California, Irvine.

Coderre, F. \& Mathieu, A. 2004. Comparison of the quality of qualitative data obtained through telephone, postal and email surveys. International Journal of Market Research, 46 (3), 347-357.

Eagle, A. 2008. Measures of success: Greenfield facility adopts evidence-based design as part of Pebble Project. Health Facilities Management, 21 (6), 12-17.

Frampton, S. 2003. Putting Patients First: Designing and Practicing Patient-Centered Care. San Francisco: Jossey-Bass AHA Press.

Garman, A., Tyler, L. \& Darnall, J. 2004. Development and validation of a 360-degree-feedback instrument for healthcare administrators. Journal of Healthcare Management, 49 (5), 307-322.

Graham, A., Papandonatos, G., Bock, B., Cobb, N., Baskin-Sommers, A., Niaura, R., \& Abrams, D. 2006. Nicotine \& Tobacco Research, 8, suppl 1, S49-S57.
Green Guide for Healthcare, n.d. About the green guide for healthcare. Retrieved October 16, 2008 from http://www.gghc.org/about.cfm.

Groves, K. 2006. View from the top: CEO perspectives on executive development and succession planning processes in healthcare organizations. Journal of Health Education Administration, 23 (1), 93-110.

Johnson, J. \& Barach, P. 2008. The role of qualitative methods in designing healthcare organizations. Environment \& Behavior, 40 (2), 191-204.

Jones, R. \& Pitt, N. 1999. Health surveys in the workplace; Comparison of postal, email and World Wide Web methods. Occupational Medicine, 49 (8), 556-558.

Marshall-Baker, A. 2006. Human and environmental health: Sustainable design for the NICU, Journal of Perinatology, 26, S31-S33.

McGraw-Hill Construction 2007. Health Care Green Building SmartMarket Report. McGraw-Hill Construction.

Vakili-Ardebili, A \& Boussabaine, A. 2007. Design ecodrivers, The Journal of Architecture, 12 (3), 315-332.

Wyden, R. \& Bennett, B. 2008. Finally, fixing healthcare: What's different now? Health Affairs, 27 (3), 689-692.

Zimmerman, G. 2007. Healthy and green. Building Operation Management, 54, 34. 